\title{
The P450 gene CYP749A16 is required for tolerance to the sulfonylurea herbicide trifloxysulfuron sodium in cotton (Gossypium hirsutum L.)
}

\author{
Gregory N. Thyssen ${ }^{1,2}$, Marina Naoumkina ${ }^{1}$, Jack C. McCarty ${ }^{3}$, Johnie N. Jenkins ${ }^{3}$, Christopher Florane ${ }^{1}$, Ping Li ${ }^{1}$ \\ and David D. Fang ${ }^{1 *}$
}

\begin{abstract}
Background: Weed management is critical to global crop production and is complicated by rapidly evolving herbicide resistance in weeds. New sources of herbicide resistance are needed for crop plants so that applied herbicides can be rotated or combined to thwart the evolution of resistant weeds. The diverse family of cytochrome P450 proteins has been suggested to be a source of detoxifying herbicide metabolism in both weed and crop plants, and greater understanding of these genes will offer avenues for crop improvement and novel weed management practices.

Results: Here, we report the identification of CYP749A16 (Gh_D10G1401) which is responsible for the natural tolerance exhibited by most cotton, Gossypium hirsutum L., cultivars to the herbicide trifloxysulfuron sodium (TFS, CGA 362622, commercial formulation Envoke). A 1-bp frameshift insertion in the third exon of CYP749A16 results in the loss of tolerance to TFS. The DNA marker designed from this insertion perfectly co-segregated with the phenotype in $2145 \mathrm{~F}_{2}$ progeny of a cross between the sensitive cultivar Paymaster HS26 and tolerant cultivar Stoneville 474, and in 550 recombinant inbred lines of a multi-parent advanced generation inter-cross population. Marker analysis of 382 additional cotton cultivars identified twelve cultivars containing the 1-bp frameshift insertion. The marker genotypes matched perfectly with phenotypes in 188 plants from the selected twelve cultivars. Virus-induced gene silencing of CYP749A16 generated sensitivity in the tolerant cotton cultivar Stoneville 474.
\end{abstract}

Conclusions: CYP749A16 located on chromosome D10 is required for TFS herbicide tolerance in cotton. This finding should add to the repertoire of tools available to farmers and breeders for the advancement of agricultural productivity.

Keywords: Acetohydroxyacid synthase, Acetolactate synthase, Cotton, Herbicide tolerance, Trifloxysulfuron sodium (TFS)

\section{Background}

The development of no-till farming has greatly increased overall efficiency of crop production by eliminating the need to expend resources on physically overturning the soil [1]. However, tillage is historically important to weed management, and competition from weeds can reduce crop yields significantly [1]. Herbicides that crops can tolerate, but weeds cannot, are tools for no-till weed management. In some cases, a transgene is introduced into the

\footnotetext{
* Correspondence: david.fang@ars.usda.gov

${ }^{1}$ Cotton Fiber Bioscience Research Unit, USDA-ARS-SRRC, New Orleans, LA 70124, USA

Full list of author information is available at the end of the article
}

crop to provide resistance to an otherwise widely effective herbicide [2, 3]. However, eventually weeds gain herbicide resistance, either by gene flow from sexually compatible crop species, or by natural mutation and selection $[4,5]$. The identification of novel genetic mechanisms to achieve herbicide resistance or tolerance in crops is one way of circumventing the continually emerging sources of resistance in weeds, and maintaining and advancing overall crop production efficiency.

Cotton, Gossypium hirsutum L., is globally the most important source of fibers for textiles [6]. Control of broadleaf weeds such as morningglory (Ipomoeapurpurea L. Roth), sicklepod (Cassia obtusifolia L.), and pigweed

(C) The Author(s). 2018 Open Access This article is distributed under the terms of the Creative Commons Attribution 4.0 International License (http://creativecommons.org/licenses/by/4.0/), which permits unrestricted use, distribution, and 
(Amaranthus retroflexus L.) with inhibitors of acetolactate synthase (ALS), is based on the tolerance of cotton plants to such herbicides [7]. Sulfonylurea herbicides, including trifloxysulfuron sodium (TFS, CGA 362622, commercial name Envoke), non-competitively bind to ALS and inhibit the synthesis of the branched-chain amino acids $[8,9]$. Resistance to such herbicides in several plant species has been attributed to certain non-synonymous changes to amino acid sequences near the herbicide binding site following mutagenesis or selection, including in Zea mays [10], Arabidopsis thaliana [11], Beta vulgaris [12], Brassica napus [13], Glycine max [14], Nicotiana tabacum [15], Triticum aestivum [16], Lolium rigidum [17], Alopecurus myosuroides [18], and Gossypium hirsutum [19]. Such mutations allow the ALS protein to function in the presence of the herbicide [8]. The man-made mutations identified in allotetraploid cotton were located in either the A or D subgenome copies of the ALS gene $[19,20]$. In cotton, a high level of herbicide resistance was achieved by stable over-expression of an altered ALS sequence [21].

Most cotton cultivars can recover after application of ALS-inhibiting herbicides, even though the ALS allele is sensitive. Tolerance in commercial cultivars does not depend on a transgene or point mutations in the ALS gene [22, 23]. Instead, tolerance of cotton to sulfonylurea herbicides is thought to be due to reduced absorption and translocation of the herbicide in conjunction with rapid metabolism [7]. Cotton leaves absorb less ${ }^{14} \mathrm{C}$-radiolabled TFS than sensitive plants like peanut (Arachis hypogaea), and the herbicide was more rapidly metabolized [7, 24].

Non-target site resistance (NTSR) is an important mechanism of herbicide resistance in weeds that often involves P450 proteins [25]. One report identified the mechanism of resistance to phenylurea herbicides as a cytochrome P450 monooxygenase protein [26]. This P450 protein was identified in Jerusalem artichoke (Helianthus tuberosus) and conferred resistance to several phenlyurea herbicides when over-expressed in Arabidopsis thaliana [27]. The resistance mechanism was shown to be metabolism of the herbicides by the P450 protein [27] which had already been shown in Zea mays [28, 29] and Triticum aestivum [30]. Nicosulfuron and bentazon-sensitive $Z$. mays lines GA209 and W703a were found to contain the same 392-base pair insertion in a P450 gene, NSF1/BEN1 [31-33]. Another cytochrome P450 gene, CYP81A6, was identified in Oryza sativa and shown to provide resistance to sulfonylurea herbicides [34]. Several studies have attributed resistance to the $\mathrm{P} 450$ family of proteins based on the observation that co-application of the pesticide malathion, a P450 inhibitor, results in loss of resistance or reduction in tolerance $[17,25,35,36]$. Due to limited genomic resources in weed species, cloning of these putative NTSR genes was not practical [35]. The P450 protein family comprises hundreds of genes in A. thaliana [37]. The draft genome of G. hirsutum contains 622 annotated cytochrome P450 genes [38].

Our earlier discovery of an TFS-sensitive cotton cultivar, Paymaster HS26, made possible this study of the genetic basis of sulfonylurea herbicide tolerance in $G$. hirsutum [39]. We previously determined that Paymaster HS26 has identical ALS sequences to tolerant cultivars, and found that a single locus on Chr D10 (also called Chromosome 20) was responsible for tolerance in a segregating $F_{2}$ population [39]. Here, we sequenced sensitive and tolerant recombinant inbred lines (RILs) of a multiparent advanced generation intercross (MAGIC) population, increased the size of the $F_{2}$ population, and screened a diverse panel of cultivated cotton varieties to link a 1-bp frameshift insertion in a cytochrome P450 gene, CYP749A16 (Gh_D10G1401) to theTFS herbicide sensitivity. We further confirmed the role of CYP749A16 in cotton by using virus induced gene silencing (VIGS) to generate sensitivity in a tolerant cotton line.

\section{Results \\ Segregation of TFS herbicide tolerance in the $F_{2}$ and MAGIC populations}

Two cotton (G. hirsutum) cultivars, Stoneville 474 (STV474) and Paymaster HS26 (HS26) were selected based on our observation of TFS sensitivity in HS26 [39]. STV474, like most cotton cultivars [22], is only transiently damaged by TFS herbicide application, and fully recovers in less than a week in field conditions [39]. To identify the genomic location of the gene responsible for TFS sensitivity in HS26, we developed a new $F_{2}$ population by crossing HS26 with the tolerant cultivar STV474. In $1695 \mathrm{~F}_{2}$ progeny plants, 1255 were tolerant while 440 were sensitive $\left(X^{2}=0.83 \mathrm{~ns}\right)$. This supports our previous conclusion that the TFS herbicide tolerance in cotton is conferred by a single dominant locus [39]. Among the eleven parents of the MAGIC population, only HS26 was sensitive. Of the 550 MAGIC RILs, twenty were sensitive.

\section{Identification of a mutant allele of CYP749A16}

A MAGIC population was developed through a half-diallel crossing scheme between eleven G. hirsutum cultivars that included both HS26 and STV474 [40]. The MAGIC population of 550 RILs and their eleven parents were sequenced with short reads. We found polymorphisms that were specific to HS26 and the twenty sensitive RILs in the vicinity of our previously reported locus and searched for their presence in all 550 RILs. One of these, at position $28,455,988$ on chromosome D10, is an insertion of an additional adenine in the third exon of a P450 gene, CYP749A16 (Gh_D10G1401) (Fig. 1). We designed a PCR-based marker (Additional file 1: Table S1) 


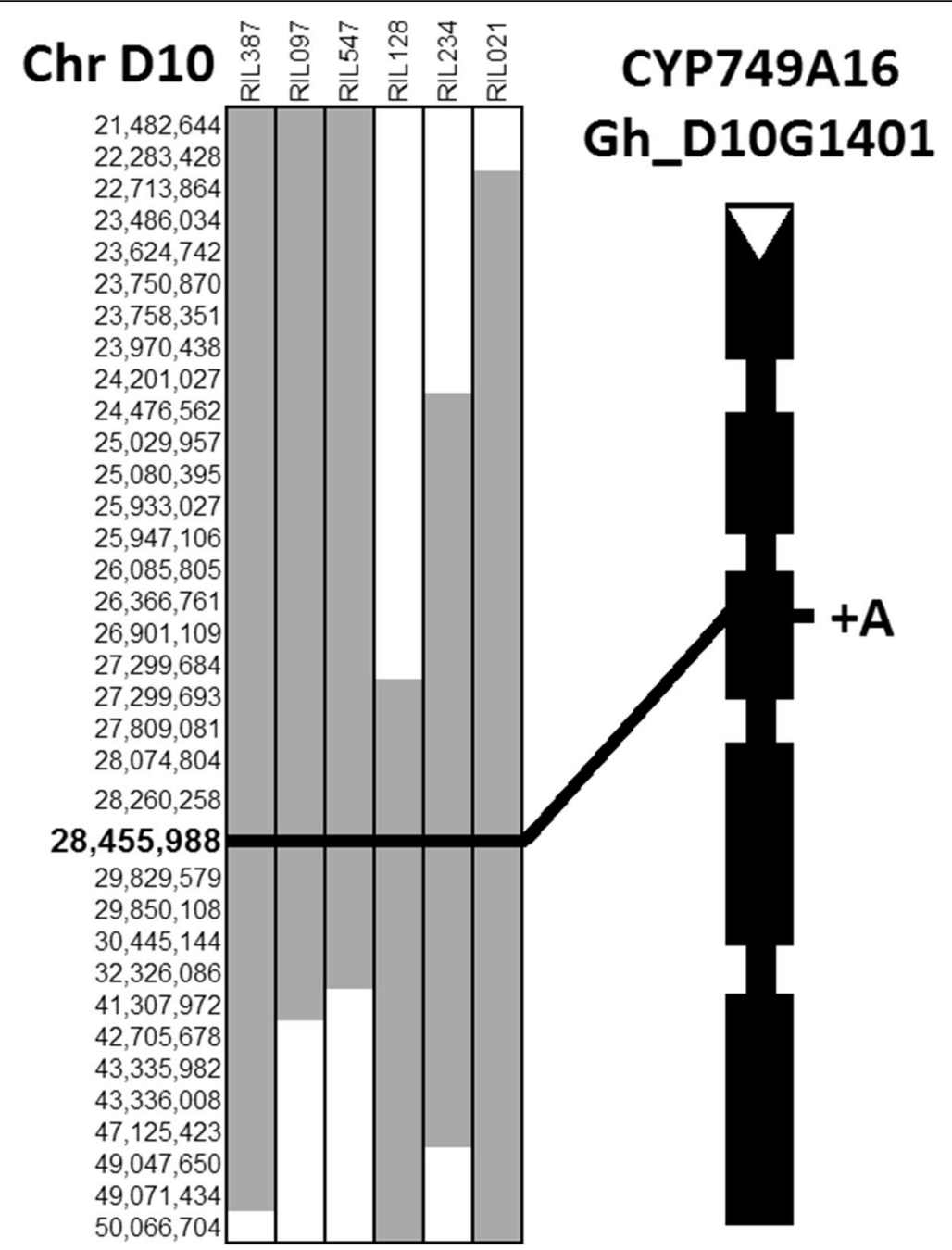

Fig. 1 Identification of a frameshift mutation in CYP749A16 (Gh_D10G1401). Polymorphisms that are specific to the trifloxysulfuron sodium (TFS) herbicide sensitive parent, Gossypium hirsutum cv Paymaster HS26 were detected in recombinant inbred lines from a MAGIC population by whole genome skim sequencing and are shown in grey, while the reference allele is white. The exon and intron structure of the candidate gene is shown with thick and thin black lines, respectively, and the location of the extra adenine in sensitive plants is labeled

and tested for the presence of the frameshift insertion in all 550 RILs, along with $2145 \mathrm{~F}_{2}$ plants derived from a cross between HS26 and STV474, and also 382 additional cotton cultivars. In the segregating $\mathrm{F}_{2}$ and MAGIC populations, only plants that were homozygous for the disrupted allele were sensitive to TFS herbicide. Of the 382 cultivars tested, the presence of the mutant allele was identified in 12 cultivars (Additional file 1: Table S2). Nine to 23 plants from each of these 12 cultivars were grown in a greenhouse, genotyped at the Gh_D10G1401 locus, and sprayed with TFS herbicide. All plants from cultivars that were homogeneous at the locus were sensitive to TFS herbicide. Seeds from cultivars that were heterogeneous at the locus, based on the initial screen of pooled DNA from multiple individuals of the same cultivar, produced sensitive and tolerant plants. The sensitivity of individually phenotyped plants to the herbicide was in perfect accord with their genotypes at the Gh_D10G1401 locus. Pedigree analysis suggested that G. hirsutum cultivar Kekchi is a common ancestor to the sensitive lines [41].

\section{Response of CYP749A16 to TFS herbicide}

We compared the dose dependent induction of CYP 749A16 transcripts in STV474 and HS26 (Fig. 2). At concentrations of $12.5 \mu \mathrm{M}$ TFS and below, the gene was only weakly expressed in each line. At and above $50 \mu \mathrm{M}$ TFS, CYP749A16 transcripts were induced in the sensitive line HS26, but CYP749A16 transcripts were only significantly induced at $3000 \mu \mathrm{M}$ TFS in the tolerant line, STV474. At this concentration the STV474 plants quickly recovered from any damage, while the HS26 plants withered and died (Fig. 3a, c). 

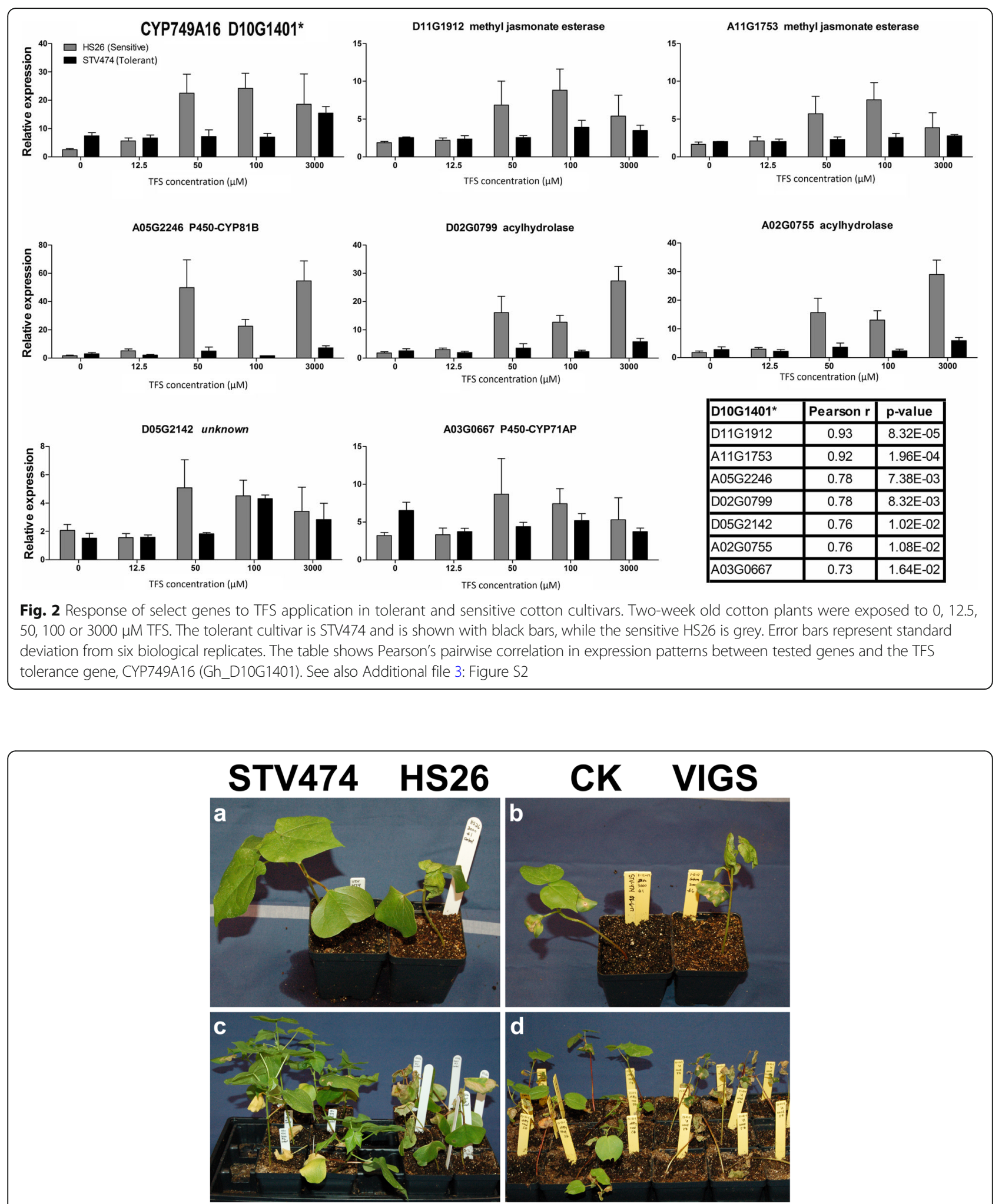

Fig. 3 Response of tolerant, sensitive and VIGS cotton plants to TFS herbicide. Three week old cotton plants shown one week after application of 3000 HM TFS herbicide. a, c Tolerant (STV474) and sensitive (HS26) cultivars. b, d Tolerant STV474 plants were infiltrated with the helper vector, pTRV1, and either an empty pTRV2 vector (CK) or with a pTRV2-D10G1401 construct to test the effect of virus-induced gene silencing (VIGS) of the CYP749A16 (Gh_D10G1401) gene on TFS tolerance. Damage to cotyledons was due to the VIGS infiltration, while damage to true leaves could be attributed to the induced TFS sensitivity 


\section{Virus-induced gene silencing (VIGS) of CYP749A16}

To confirm the involvement of CYP749A16 in tolerance to TFS herbicide with an independent line of evidence, we constructed a virus induced gene silencing vector based on the tobacco rattle virus to suppress gene expression in tolerant STV474 plants. We optimized the specificity of the targeting region (See Methods and Additional file 2: Figure S1, Additional file 1: Table S3) and cloned 350-bp of coding sequence for the reference Gh_D10G1401 gene into the pTRV2 vector (Additional file 1: Table S4). A week after infiltration, when new tissues had emerged including two true leaves, we applied TFS herbicide at $3000 \mu \mathrm{M}$, the rate that we found to induce CYP749A16 expression in STV474 plants (Fig. 2). One week later, the true leaves of the VIGS plants withered and died, while the control plants had no obvious damage to their true leaves (Fig. 3b, d). The cotyledons of both the control and VIGS plants were damaged during the infiltration procedure.

\section{Co-expression analysis}

To explore the possibility that more genes from cotton, beyond CYP749A16, are involved in generating TFS herbicide tolerance, we examined expression of select genes by RT-qPCR. We queried the ccNET database with Gh_D10G1401 to find genes that are often co-expressed [42]. From the list, we selected genes with the highest mutual ranks, plus high ranking P450 genes and genes with no known ortholog in Arabidopsis. We tested twenty genes in STV474 and HS26 plants that had been challenged with different concentrations of TFS herbicide. Of these, seven showed significant positive correlation $(>0.7)$ (Fig. 2) while thirteen showed lower or negative correlation $(<0.7)$ with Gh_D10G1401 (Additional file 3: Figure S2).

\section{Discussion and conclusions}

We previously identified sensitivity to the TFS herbicide in cotton cultivar Paymaster HS26 and demonstrated that this was not due to mutations in the acetolactate synthase (ALS) gene that is the target of the herbicide [39]. Here, we have shown that the gene responsible for TFS tolerance in cotton is a cytochrome P450 gene, CYP749A16 (Gh_D10G1401) and that sensitive cotton cultivars carry a 1-bp frameshift insertion in the third exon of the gene. We are able to conclude that CYP749A16 is necessary for TFS tolerance in cotton, by the co-segregation or association of the frameshift insertion in segregating and cultivated populations (Fig. 1 and Additional file 1: Table S2). This was further confirmed by our observation that VIGS of CYP749A16 was able to induce sensitivity to TFS in a tolerant variety (Fig. 3). Since related P450 genes have been shown to confer herbicide resistance by catalyzing chemical modifications to herbicides, it is not surprising to have found that a P450 gene is necessary for TFS tolerance in cotton. Indeed cotton cultivars, including STV474, were reported to exhibit increased damage when TFS is mixed with malathion, a P450 inhibitor, which could be taken as evidence of $\mathrm{P} 450$ mediated metabolism of the TFS herbicide in cotton $[43,44]$.

The cytochrome P450 family comprises 622 genes in G. hirsutum, and some plant species have experienced lineage-specific expansions and losses of subfamilies [45, 46]. Of particular interest is the loss of the CYP749 family from the Brassicales which includes Arabidopsis, despite their presence in the sister group Malvales, which includes cotton, and most other rosids [46]. While we have demonstrated that CYP749A16 is required for TFS tolerance in cotton, further work is required to determine if it is sufficient to generate resistance in another plant species. We began the search for additional proteins that may also be involved in TFS detoxification by examining the expression of select genes that are often co-expressed with CYP749A16. We found that some of the select genes were similarly induced by TFS as CYP749A16 (Fig. 2), but others were not (Additional file 3: Figure S2). Further, more exhaustive expression analysis should be conducted in the future.

There does not appear to be a functional A-subgenome homeolog of Gh_D10G1401, in the reference genome we used or cultivars we studied [38]. At the homeologous location on Chr A10 is a sequence with high homology to Gh_D10G1401, but it is missing an adenine residue at A10:54,681,293, which results in a frameshift mutation, rendering this sequence an unannotated pseudogene (Additional file 1: Table S6). This observation helps explain the simple recessive nature of the TFS sensitivity locus in an allotetraploid crop.

Our earlier genetic mapping of the TFS-tolerance locus placed CYP749A16 outside of the candidate interval by $3.5 \mathrm{Mb}$ [39]. That work relied on twelve SSR-markers and $450 \mathrm{~F}_{2}$ progeny, while here we used whole genome sequencing of 550 RILs from an eleven-parent MAGIC population to identify the frameshift mutation, which we then found to be completely linked in $2145 \mathrm{~F}_{2}$ progeny and predictive in a diversity panel of 384 varieties. This demonstrates the importance, in any genetic mapping project, to eventually find the causative mutation, rather than simply flanking markers. The marker for the causative mutation we describe here could be used by cotton breeders to eliminate TFS sensitivity from cotton cultivars, or to deliberately select for sensitivity, which may be useful in some crop-rotation systems. It is possible that transgenic introduction of CYP749A16 to other crops would confer TFS resistance which would add to the tools available to breeders and farmers for no-till weed management.

\section{Methods}

Plant materials

Crosses between G. hirsutum cv. Paymaster HS26 (HS26) and G. hirsutum cv Stoneville 474 (STV474) were made 
to establish the $F_{1}$ population, which was self-pollinated to produce the $F_{2}$. The $F_{2}$ seeds were planted in the Plant Science Research Farm at Mississippi State, MS, USA. During the plant growing season, standard conventional field practices were followed. In addition to the $450 \mathrm{~F}_{2}$ individuals previously studied [39], we genotyped and phenotyped an additional $1695 \mathrm{~F}_{2}$ individuals in 2014 in the same way, for the present study.

A MAGIC population was developed through a half-diallel crossing scheme between eleven parents that included both HS26 and STV474 [40]. The $55 \mathrm{~F}_{1}$ were considered as 55 half-sib families and designated as Cycle $0\left(C_{0}\right)$. Five cycles $\left(C_{1}\right.$ to $\left.C_{5}\right)$ of random mating were made by bulking an equal amount of pollen from each of the 55 families. After that, the plants were self-pollinated for six generations using single seed descent to produce 550 RILs [40, 47]. The eleven parents and 550 RILs were planted in the Plant Science Research Farm at Mississippi State, MS, USA in 2010. Each RIL was planted in two $12 \mathrm{~m}$ plots consisting of about 120 plants per replicate. Of the 550 RILs, twenty were sensitive to TFS.

Three hundred eighty-four cotton cultivars, including HS26 and STV474, (Additional file 1: Table S2) that had been included in the National Cotton Variety Trials (NCVT) over the past sixty years were used to create a diversity panel. For each cultivar, young leaves from about ten seedlings were collected for DNA extraction.

\section{Field TFS herbicide treatment}

The parental cultivars, $F_{2}$ plants and MAGIC RILs were subjected to over-the-top application of TFS along with the $25 \% \mathrm{w} / \mathrm{w}$ additional proprietary inactive ingredients in the commercially available herbicide formulation, Envoke (Syngenta Crop Protection Inc., Greensboro, $\mathrm{NC}$, USA) six weeks after planting at a rate of $10.5 \mathrm{~g}$ TFS/ ha and volume of $186.8 \mathrm{l} /$ ha (equivalent to $100 \mu \mathrm{M}$ TFS). The phenotypes were observed as tolerant or sensitive based on observations of damage to plants one and two weeks later.

\section{Greenhouse TFS herbicide treatment}

Out of the 384 cultivars comprising the diversity panel, thirteen including Paymaster HS26 had a sensitive or heterogeneous genotype at the Gh_D10G1401 locus (Additional file 1: Table S2). Except HS26, the other twelve cultivars were planted in 5-gal pots in a greenhouse in New Orleans, LA, USA in January, 2016. Nine to 23 seedlings were tested for each cultivar. Six-week-old seedlings were sprayed over-the-top with Envoke herbicide (100 $\mu$ M TFS). Before herbicide treatment, a young leaf was collected from each individual plant for DNA extraction. A total of 188 seedlings were used.

\section{Growth chamber TFS herbicide treatment}

STV474 and HS26 seeds were first germinated in a greenhouse. After emergence, seedlings were moved into a $22{ }^{\circ} \mathrm{C}$ growth chamber under a 12-h light and 12-h dark cycle. After two weeks, at the complete expansion of two true leaves, plants were sprayed with different concentrations of Envoke herbicide (0, 12.5, 50, 100 or $3000 \mu \mathrm{M}$ TFS). Each treatment group contained six plants. Leaf tissues were collected one week later for RNA isolation that would be used for RT-qPCR.

\section{DNA and RNA isolation}

Young leaves were collected from parental cultivars, $2145 \mathrm{~F}_{2}$ progeny, 550 MAGIC RILs, 384 NCVT cultivars, and 188 greenhouse-grown plants from a subset of 12 cultivars. DNA was isolated as described previously [48]. RNA was isolated from leaves according to the procedures used before [49].

\section{Genome sequence analysis}

The whole genomes of eleven MAGIC parents were sequenced at $20 \times$ coverage and all 550 RILs were sequenced at $3 \times$ coverage with Illumina short read (101 or 150-bp) paired-end sequencing with 300 to 500 -bp inserts. Genome sequencing was conducted by Novogene Corporation (Chula Vista, CA, USA). Sequence reads were aligned to the NBI G. hirsutum cv TM-1 reference genome [38] with GSNAP software [50]. Variants were identified with samtools and bcftools software [51]. We filtered the variants to find polymorphisms that were unique to HS26 and shared by all twenty TFS herbicide sensitive RILs. Among such polymorphisms was an additional adenosine residue after position 28,455,988 on Chr D10 (Fig. 1). This was the only such polymorphism detected in the coding sequence of a gene. Since this mutation would result in a frameshift disruption of the P450 gene CYP749A16 (Gh_D10G1401), we designed a PCR-based marker to detect this allele. The primers (Additional file 1: Table S1) were used to detect the insertion allele in all the plant materials used in this study. The marker was run in a SYBR master mix on a BioRad CFX qPCR machine (Hercules, CA, USA) so that observations of $\mathrm{Ct}$ values could be used to determine presence or absence of amplicons, as before [52].

\section{Virus-induced gene silencing}

A 350-bp fragment of CYP749A16 was synthesized based on the reference sequence (Additional file 1: Table S4) [38]. The site was chosen by SGN VIGS Tool software [53] using the NBI reference genome [38] (Additional file 2: Figure S1 and Additional file 1: Table S3). This fragment was cloned into EcoRI-KpnI digested pTRV2 to produce a VIGS vector named pTRV2-D10G1401. The pTRV1 helper plasmid, pTRV2- D10G1401, along with VIGS 
positive control pTRV2-Cla1 and negative control empty vector pTRV2-0 were introduced into the Agrobacterium strain GV3101 by electroporation (Bio-Rad, Hercules, CA, USA). A previously published protocol was used for the VIGS assay [54]. Briefly, the transformed Agrobacterium colonies were grown overnight at $28{ }^{\circ} \mathrm{C}$ in an antibiotic selection medium containing kanamycin $50 \mathrm{mg} / \mathrm{L}$ and gentamycin $25 \mathrm{mg} / \mathrm{L}$. Agrobacterium cells were collected and re-suspended in infiltration medium (10 $\mathrm{mM} \mathrm{MgCl}_{2}$, $10 \mathrm{mM}$ MES and $200 \mu \mathrm{M}$ acetosyringone), adjusted to $\mathrm{OD} 600=1.5$. Agrobacterium strains containing pTRV1 and pTRV2 vectors were mixed at a ratio of 1:1. Seedlings of STV474 with mature cotyledons but without a visible true leaf (seven days after germination) were infiltrated by inserting the Agrobacterium suspension into the cotyledons via a syringe. Each treatment group contained nine plants. The plants were grown in pots at $22{ }^{\circ} \mathrm{C}$ in a growth chamber under a 12-h light and 12-h dark cycle. After two weeks, plants were sprayed with herbicide at the concentration of $3000 \mu \mathrm{M}$ TFS (Fig. 3b, d).

\section{Co-expression analysis}

The ccNet database was queried for co-expressed genes of Gh_D10G1401 [42]. Twenty genes, including four P450 genes, and eight genes without an obvious ortholog in Arabidopsis were selected for analysis and specific RT-qPCR primers were designed (Additional file 1: Table S5). Expression was tested on the STV474 and HS26 plants that had been exposed to a range of TFS concentrations. Pearson correlation coefficients and $p$-values were calculated to identify genes that were co-expressed with Gh_D10G1401 in response to TFS application (Fig. 2 and Additional file 3: Figure S2).

\section{Additional files}

Additional file 1: Table S1. qPCR Genetic marker primers used in this study. Table S2. List of 384 cotton cultivars included in the diversity panel and their genotype at the Gh_D10G1401 locus. Table S3. Specificity of gene fragment for VIGS in NBI reference sequences. Table S4. Gene fragment for VIGS. Table S5. RT-qPCR Primers used in this study. Table S6. Multiple alignment of Gh_D10G1401 from Paymaster HS26 and wild-type cotton, including potential homeologous region on Chr A10. (DOCX 38 kb)

Additional file 2: Figure S1. Design of VIGS target sequence. The SGN VIGS Tool software selected the 350-bp targeting sequence (yellow region) from the NBI reference genome for cotton, Gossypium hirsutum cv. TM-1. The full length coding sequence of Gh_D10G1401 was chopped into all 1542 possible 21-mers. These 21-mers were aligned to annotated coding sequences, allowing one mismatch. Off target alignments of 21-mers are shown in red. (JPG $683 \mathrm{~kb}$ )

Additional file 3: Figure S2. Response of additional genes to TFS application in tolerant and sensitive cotton cultivars. Two-week old cotton plants were exposed to $0,12.5,50,100$ or $3000 \mu \mathrm{M}$ TFS. The tolerant cultivar is STV474 and is shown with black bars, while the sensitive HS26 is grey. Error bars represent standard deviation from six biological replicates. The table shows Pearson's pairwise correlation in expression patterns between tested genes and CYP749A16 (Gh_D10G1401). See also Fig. 2. (JPG 5645 kb)

\section{Acknowledgements}

We thank Mr. Russell Hayes for assisting with the field experiments. Mention of trade names or commercial products in this article is solely for the purpose of providing specific information and does not imply recommendation or endorsement by the U. S. Department of Agriculture that is an equal opportunity provider and employer.

\section{Funding}

This research was funded by United States Department of Agriculture-Agricultural Research Service CRIS project\# 6054-21000-017-00D.

\section{Availability of data and materials}

All relevant data is contained within this manuscript and its supplemental files. Plant materials are commercially available cultivars.

\section{Authors' contributions}

GNT, MN, JCM, JNJ, DDF designed the experiments and analyzed data. JNJ and DDF conceived the project. GNT analyzed sequence data, designed markers, and wrote the paper with input from all authors; GNT and MN designed and assembled constructs; MN, CF and DDF carried out VIGS and greenhouse experiments; JCM and JNJ developed populations and conducted field experiments; PL and DDF isolated DNA and tested markers. DDF coordinated the project. All authors read and approved the final manuscript.

\section{Ethics approval and consent to participate}

Not applicable

\section{Consent for publication}

All authors have read and approved the manuscript for publication.

\section{Competing interests}

The authors declare no competing financial interests.

\section{Publisher's Note}

Springer Nature remains neutral with regard to jurisdictional claims in published maps and institutional affiliations.

\section{Author details}

${ }^{1}$ Cotton Fiber Bioscience Research Unit, USDA-ARS-SRRC, New Orleans, LA 70124, USA. ${ }^{2}$ Cotton Chemistry and Utilization Research Unit,

USDA-ARS-SRRC, New Orleans, LA 70124, USA. ${ }^{3}$ Genetics \& Sustainable

Agriculture Research Unit, USDA-ARS, Mississippi State, MS 39762, USA.

Received: 21 November 2017 Accepted: 2 September 2018

Published online: 10 September 2018

\section{References}

1. Montgomery DR. Soil erosion and agricultural sustainability. Proc Natl Acad Sci. 2007;104:13268-72.

2. Behrens MR, Mutlu N, Chakraborty S, Dumitru R, Jiang WZ, LaVallee BJ, Herman PL, Clemente TE, Weeks DP. Dicamba resistance: enlarging and preserving biotechnology-based weed management strategies. Science. 2007;316:1185-8.

3. Wright TR, Shan G, Walsh TA, Lira JM, Cui C, Song P, Zhuang M, Arnold NL, Lin G, Yau K. Robust crop resistance to broadleaf and grass herbicides provided by aryloxyalkanoate dioxygenase transgenes. Proc Natl Acad Sci. 2010;107:20240-5.

4. Green JM. Review of glyphosate and ALS-inhibiting herbicide crop resistance and resistant weed management. Weed Technol. 2007;21:547-58.

5. Baerson SR, Rodriguez DJ, Tran M, Feng Y, Biest NA, Dill GM. Glyphosateresistant goosegrass. Identification of a mutation in the target enzyme 5-enolpyruvylshikimate-3-phosphate synthase. Plant Physiol. 2002;129:1265-75.

6. Paterson AH, Wendel JF, Gundlach H, Guo H, Jenkins J, Jin D, Llewellyn D, Showmaker KC, Shu S, Udall J, et al. Repeated polyploidization of Gossypium genomes and the evolution of spinnable cotton fibres. Nature. 2012:492:423-7.

7. Askew SD, Wilcut JW. Absorption, translocation, and metabolism of foliar-applied CGA 362622 in cotton, peanut, and selected weeds. Weed Sci. 2002;50:293-8.

8. McCourt JA, Pang SS, King-Scott J, Guddat LW, Duggleby RG. Herbicidebinding sites revealed in the structure of plant acetohydroxyacid synthase. Proc Natl Acad Sci. 2006;103:569-73. 
9. Chaleff RS, Mauvais CJ. Acetolactate synthase is the site of action of two sulfonylurea herbicides in higher plants. Science. 1984;224:1443-5.

10. Newhouse K, Singh B, Shaner D, Stidham M. Mutations in corn (Zea mays L.) conferring resistance to imidazolinone herbicides. Theor Appl Genet. 1991;83:65-70.

11. Haughn G, Somerville C. Sulfonylurea-resistant mutants of Arabidopsis thaliana. Mol Gen Genet. 1986;204:430-4.

12. Wright TR, Penner D. Cell selection and inheritance of imidazolinone resistance in sugarbeet (Beta vulgaris). Theor Appl Genet. 1998;96(5):612-20.

13. Swanson EB, Herrgesell MJ, Arnoldo M, Sippell DW, Wong RSC. Microspore mutagenesis and selection: canola plants with field tolerance to the imidazolinones. Theor Appl Genet. 1989;78:525-30.

14. Sebastian SA, Fader GM, Ulrich JF, Forney DR, Chaleff RS. Semidominant soybean mutation for resistance to sulfonylurea herbicides. Crop Sci. 1989;29:1403-8.

15. Chaleff RS, Ray TB. Herbicide-resistant mutants from tobacco cell cultures. Science. 1984;223:1148-51.

16. Pozniak CJ, Birk IT, O'Donoughue LS, Ménard C, Hucl PJ, Singh BK. Physiological and molecular characterization of mutation-derived imidazolinone resistance in spring wheat. Crop Sci. 2004;44:1434-43.

17. Yu Q, Abdallah I, Han H, Owen M, Powles S. Distinct non-target site mechanisms endow resistance to glyphosate, ACCase and ALS-inhibiting herbicides in multiple herbicide-resistant Lolium rigidum. Planta. 2009;230:713-23.

18. Petit C, Duhieu B, Boucansaud K, Délye C. Complex genetic control of non-target-site-based resistance to herbicides inhibiting acetyl-coenzyme a carboxylase and acetolactate-synthase in Alopecurus myosuroides Huds. Plant Sci. 2010;178:501-9.

19. Rajasekaran K, Grula JW, Anderson DM. Selection and characterization of mutant cotton (Gossypium hirsutum L.) cell lines resistant to sulfonylurea and imidazolinone herbicides. Plant Sci. 1996;119:115-24.

20. Grula JW, Hudspeth RL, Hobbs SL, Anderson DM. Organization, inheritance and expression of acetohydroxyacid synthase genes in the cotton allotetraploid Gossypium hirsutum. Plant Mol Biol. 1995;28:837-46.

21. Rajasekaran K, Grula J, Hudspeth R, Pofelis S, Anderson D. Herbicide-resistant Acala and Coker cottons transformed with a native gene encoding mutant forms of acetohydroxyacid synthase. Mol Breed. 1996;2:307-19.

22. Porterfield D, Wilcut JW, Clewis SB, Edmisten KL. Weed-free yield response of seven cotton (Gossypium hirsutum) cultivars to CGA-362622 postemergence. Weed Technol. 2002;16:180-3.

23. Porterfield D, Wilcut JW, Wells JW, Clewis SB. Weed management with CGA362622 in transgenic and nontransgenic cotton. Weed Sci. 2003;51:1002-9.

24. Richardson RJ, Hatzios KK, Wilson HP. Absorption, translocation, and metabolism of CGA 362622 in cotton and two weeds. Weed Sci. 2003;51:157-62.

25. Yuan JS, Tranel PJ, Stewart CN Jr. Non-target-site herbicide resistance: a family business. Trends Plant Sci. 2007;12:6-13.

26. Robineau T, Batard Y, Nedelkina S, Cabello-Hurtado F, LeRet M, Sorokine O, Didierjean L, Werck-Reichhart D. The chemically inducible plant cytochrome P450 CYP76B1 actively metabolizes phenylureas and other xenobiotics. Plant Physiol. 1998;118:1049-56.

27. Didierjean L, Gondet L, Perkins R, Lau SM, Schaller H, O'Keefe DP, WerckReichhart D. Engineering herbicide metabolism in tobacco and Arabidopsis with CYP76B1, a cytochrome P450 enzyme from Jerusalem artichoke. Plant Physiol. 2002;130:179-89.

28. Barrett M. Metabolism of herbicides by cytochrome P450 in corn. Drug Metabol Drug Interact. 1995;12:299-315.

29. Persans MW, Schuler MA. Differential induction of cytochrome P450mediated triasulfuron metabolism by naphthalic anhydride and triasulfuron. Plant Physiol. 1995;109:1483-90.

30. Frear DS. Wheat microsomal cytochrome P450 monooxygenases: characterization and importance in the metabolic detoxification and selectivity of wheat herbicides. Drug Metabol Drug Interact. 1995;12:329-57.

31. Nordby JN, Williams MM, Pataky JK, Riechers DE, Lutz JD. A common genetic basis in sweet corn inbred $\mathrm{Cr} 1$ for cross sensitivity to multiple cytochrome P450-metabolized herbicides. Weed Sci. 2008;56:376-82.

32. Williams MM, Pataky JK. Genetic basis of sensitivity in sweet corn to tembotrione. Weed Sci. 2008:56:364-70.

33. Pataky JK, Meyer MD, Bollman JD, Boerboom CM, Williams MM. Genetic basis for varied levels of injury to sweet corn hybrids from three cytochrome P450-metabolized herbicides. J Amer Soc Hort Sci. 2008;133:438-47.

34. Pan G, Zhang X, Liu K, Zhang J, Wu X, Zhu J, Tu J. Map-based cloning of a novel rice cytochrome P450 gene CYP81A6 that confers resistance to two different classes of herbicides. Plant Mol Biol. 2006;61:933-43.
35. Délye C. Unravelling the genetic bases of non-target-site-based resistance (NTSR) to herbicides: a major challenge for weed science in the forthcoming decade. Pest Manag Sci. 2013;69:176-87.

36. Owen MJ, Goggin DE, Powles SB. Non-target-site-based resistance to ALSinhibiting herbicides in six Bromus rigidus populations from western Australian cropping fields. Pest Manag Sci. 2012;68:1077-82.

37. Nelson DR, Schuler MA, Paquette SM, Werck-Reichhart D, Bak S. Comparative genomics of rice and Arabidopsis. Analysis of 727 cytochrome P450 genes and pseudogenes from a monocot and a dicot. Plant Physiol. 2004;135:756-72.

38. Zhang T, Hu Y, Jiang W, Fang L, Guan X, Chen J, Zhang J, Saski CA, Scheffler BE, Stelly DM, et al. Sequencing of allotetraploid cotton (Gossypium hirsutum L. acc. TM-1) provides a resource for fiber improvement. Nature Biotechnol. 2015;33:531-7.

39. Thyssen G, McCarty JC, Li P, Jenkins JN, Fang DD. Genetic mapping of nontarget-site resistance to a sulfonylurea herbicide (Envoke ${ }^{\circledast}$ ) in upland cotton (Gossypium hirsutum L.). Mol Breed. 2014;33:341-8.

40. Jenkins JN, McCarty JC, Gutierrez OA, Hayes RW, Bowman DT, Watson CE, Jones DC. Registration of RMUP-C5, a random mated population of upland cotton germplasm. J Plant Regist. 2008;2:239-42.

41. Bowman DT, Gutierrez OA, Percy RG, Calhoun DS, May OL: Pedigrees of upland and pima cotton cultivars released between 1970 and 2005. Mississippi State Univ, Mississippi State, MS 2007, Mississippi Agricultural and Forestry Experimental Station Bulletin \# 1155: http://mafes.msstate.edu/ publications/bulletins/b1155.pdf

42. You Q, Xu W, Zhang K, Zhang L, Yi X, Yao D, Wang C, Zhang X, Zhao X, Provart NJ. cCNET: database of co-expression networks with functional modules for diploid and polyploid Gossypium. Nucleic Acids Res. 2017;45:D1090-9.

43. Minton B, Matocha M, Senseman SA. The influence of malathion on trifloxysulfuron absorption and translocation in cotton. J Cotton Sci. 2008;12:48-52.

44. Minton BW, Senseman SA, Cothren JT, Chandler JM, Wells JW. Cotton response to CGA-362622 applied alone and in combination with selected insecticides. Weed Technol. 2005;19:244-50.

45. Nelson DR. The cytochrome p450 homepage. Hum Genomics. 2009;4:59-65.

46. Nelson DR, Ming R, Alam M, Schuler MA. Comparison of cytochrome P450 genes from six plant genomes. Tropical Plant Biol. 2008;1:216-35.

47. Islam MS, Thyssen GN, Jenkins JN, Zeng L, Delhom CD, McCarty JC, Deng DD, Hinchliffe DJ, Jones DC, Fang DD. A MAGIC population-based genome-wide association study reveals functional association of GhRBB1_A07 gene with superior fiber quality in cotton. BMC Genomics. 2016;17:903.

48. Fang DD, Xiao J, Canci PC, Cantrell RG. A new SNP haplotype associated with blue disease resistance gene in cotton (Gossypium hirsutum L.). Theor Appl Genet. 2010;120:943-53.

49. Naoumkina M, Thyssen GN, Fang DD. RNA-seq analysis of short fiber mutants Ligon-lintless-1 (li 1 ) and - 2 (li 2 ) revealed important role of aquaporins in cotton (Gossypium hirsutum L.) fiber elongation. BMC Plant Biol. 2015;15:65.

50. Wu TD, Nacu S. Fast and SNP-tolerant detection of complex variants and splicing in short reads. Bioinformatics. 2010;26:873-81.

51. Li H, Handsaker B, Wysoker A, Fennell T, Ruan J, Homer N, Marth G, Abecasis G, Durbin R, Genome Project Data Processing S. The sequence alignment/map format and SAMtools. Bioinformatics. 2009;25:2078-9.

52. Thyssen GN, Fang DD, Turley RB, Florane C, Li P, Naoumkina M. Next generation genetic mapping of the Ligon-lintless-2 (li 2) locus in upland cotton (Gossypium hirsutum L.). Theor Appl Genet. 2014;127:2183-92.

53. Fernandez-Pozo N, Rosli HG, Martin GB, Mueller LA. The SGN VIGS tool: userfriendly software to design virus-induced gene silencing (VIGS) constructs for functional genomics. Mol Plant. 2015;8:486-8.

54. Gao X, Britt RC Jr, Shan L, He P. Agrobacterium-mediated virus-induced gene silencing assay in cotton. J Vis Exp. 2011;(54):e2938. 